\title{
¿Qué bebemos cuando bebemos? El papel del acetaldehído en el consumo de alcohol
}

\author{
Carles Sanchis; Carlos M. G. Aragón \\ Area de Psicobiologia. Universtitat Jaume I. Castelló. \\ Enviar correspondencia a: \\ Carlos M.G. Aragón. Area de Psicobiologia. Universtitat Jaume I. Campus de Riu Sec. Apartat. 8029 AP. 12071 Castelló. \\ Tel.: 964-729835. Fax: 964-729267. E-mail: aragon@psb.uji.es
}

\section{RESUMEN}

Aunque el alcohol etílico (etanol) es, posiblemente, la droga de abuso, más consumida en la sociedad occidental, los mecanismos de acción del etanol en el sistema nervioso central (SNC) siguen siendo desconocidos. Este hecho ha dificultado en gran medida el desarrollo de estrategias farmacológicas eficaces en el tratamiento de su consumo excesivo o alcoholismo. Sin duda, gran parte de estas dificultades derivan de las propiedades fisico-químicas de esta sustancia que la incapacitan para actuar de forma esterocomplementaria con un receptor. En los últimos años se ha propuesto que un gran número de efectos observados tras la administración/ consumo de etanol podrían estar mediados por el primer metabolito de esta sustancia, el acetaldehído, producido en el mismo SNC a través del enzima catalasa. Actualmente, existe un amplio corpus de datos experimentales que avalan dicha propuesta lo que habilita nuevos objetivos moleculares y estrategias farmacológicas (tales como la inactivación del acetaldehído) en la búsqueda de recursos terapéuticos para combatir el consumo excesivo de alcohol.

Palabras clave: Etanol, alcohol, acetaldehído, catalasa, aldehido deshidrogenada, penicillamina.

\begin{abstract}
Although ethyl alcohol (ethanol) is the most widely consumed drug in the Western society, ethanol mechanisms of action in the Central Nervous System (CNS) remain unknown. In consequence, the development of pharmacological strategies to treat excessive alcohol consumption and alcoholism has proven to be difficult. A major difficulty in those attempts arises from the molecular properties of ethanol, which do not allow a sterocomplementary binding to any known receptor. Therefore, over the last years, it has been proposed that a large number of effects observed alter ethanol administration/ consumption might be actually mediated by its first metabolite, namely acetaldehyde, produced inside the CNS via catalase activity. Nowadays, a large number of evidences support this proposal, leading the possibility of new pharmacological strategies (i.e. pharmacological inactivation of acetaldehyde) in the management of alcohol excessive consumption.
\end{abstract}

Key words: Ethanol, alcohol, Alcoholism, acetaldehyde, cabalase, penicillamine.

lismo cerebral previo, siendo el acetaldehído, primer metabolito oxidativo del etanol, el principal responsable de dichos efectos. A lo largo de este comentario aportaremos un resumen de los indicios que sustentan esta hipótesis y evaluaremos las posibles implicaciones que la confirmación de la misma pudiera tener para nuestra comprensión de los mecanismos de acción del etanol en el Sistema Nervioso Central (SNC) y para la terapéutica del consumo excesivo de alcohol y/ o alcoholismo. Asimismo, incorporamos un breve listado de referencias bibliográficas que pueden ser utilizadas para ampliar aquellos aspectos que, por la naturaleza de este comentario, se presentan de forma esquemática. 


\section{EL ETANOL UNA DROGA SIN “RECEPTOR”}

Las sustancias psicoactivas son aquellas capaces de modificar el comportamiento y el origen de tales cambios depende de su habilidad para alterar el funcionamiento del SNC. En este sentido, conocemos los sitios de actuación donde la mayoría de drogas de abuso ejercen sus acciones primarias. Estas acciones dependen de la interacción entre las drogas y determinadas moléculas endógenas que actúan como "dianas" para dichas sustancias, y debido a que estas dianas son en muchos casos proteínas implicadas en la transmisión sináptica, el resultado inicial de dichas interacciones es un cambio en la excitabilidad de aquellos grupos neuronales que las poseen y/o en aquellos relacionados con 'estos. Así, algunas drogas de abuso se comportan como agonistas o antagonistas de determinados receptores (ej. THCreceptores $\mathrm{CB}$, morfina, receptores $\mathrm{MU}$ ), interactúan con los mecanismos de exocitosis de los neurotransmisores (anfetamina) o con su recaptación (cocaína). Estas interacciones son muy específicas en tanto que derivan de la complementariedad en la estructura químicas de ambas moléculas, la droga y su "receptor" 1 , al modo de una llave y una cerradura. Por otra parte, como resultado de estas acciones iniciales, las drogas de abuso son capaces de promover cambios de mayor duración en el SNC que no pocas veces requieren cambios en el patrón de expresión génica en dichos grupos celulares.

A diferencia de la mayoría de drogas de abuso, el etanol es capaz de cambiar la actividad de un gran número de proteínas implicadas en la comunicación sináptica, pero no parece establecer interacciones específicas con ninguna de ellas. Este hecho se debe a las características estructurales de esta molécula, que es muy sencilla (lo que la habilita para interactuar con un gran número de sustratos) y escasamente reactiva (lo que parece impedir el establecimiento de reacciones químicas relevantes). Así, y agravado por su distribución generalizada en el SNC, la búsqueda de un mecanismo de acción primario para el etanol ha sido infructuosa. No es, pues, extraño que en muchas ocasiones se la describa como una droga con una actuación generalizada en el SNC (ej. Actuando como un agente desestabilizador de las membranas celulares) o bien se capitalice una sóla de sus acciones moleculares (ej. Agonismo funcional del receptor GABAa) y se ignoren el resto de las mismas. Sin embargo, estas dos aproximaciones son igualmente incorrectas, ya que no son capaces de incorporar la complejidad de los efectos derivados del consumo/ administración de alcohol, que no son reproducidos por otros agentes capaces de alterar las membranas celulares (ej. Anestésicos volátiles) o por agentes selectivos de los mecanismos de acción propuestos (ej. Agonistas GABAa). Es por ello que el etanol puede seguir siendo considerado como "una droga sin receptor", un hecho que complica notablemente nuestra comprensión de sus acciones el SNC y reduce nuestra posibilidad de modificarlas.

\section{UNA ALTERNATIVA EXPLICATIVA: EL ACETALDEHÍDO}

Ya que las características moleculares del etanol no parecen corresponderse con la especificidad y complejidad de sus efectos, se ha propuesto que quizás el etanol no sea el agente molecular que propicia dichos cambios. Así, desde hace más de 30 años, el interés de algunos investigadores se ha desplazado hacia la búsqueda de algún agente molecular relacionado con el etanol capaz de dar cuenta de sus efectos. En este sentido, la propuesta con mayor capacidad heurística y que ha recibido un mayor respaldo experimental ha sido la posible implicación del acetaldehído, primer metabolito oxidativo del etanol, en los efectos neurobiológicos y conductuales derivados del consumo/ administración de alcohol.

El etanol se metaboliza en acetaldehido por oxidación. En situaciones de consumo moderado, esta transformación acontece fundamentalmente en el hígado y se halla mediada por la enzima alcohol deshidrogenasa (ADH). Existen otros dos sistemas enzimáticos hepáticos, el llamado MEOS (sistema microsomal oxidativo del etanol) y el mediado por la catalasa, los cuales tienen un papel significativo, ante elevadas concentraciones de etanol. Sin embargo, este acetaldehido periféricamente formado difícílmente puede alcanzar el SNC, ya que en el mismo hígado, así como en la barrera hematoencefálica, existe una importante vía de degradación de este compuesto mediada por el enzima aldehido deshidrogenasa (ALDH) que reduce al mínimo la posibilidad de que exista acetaldehido circulante. Por tanto, para que el acetaldehido pudiera reaccionar con el sustrato neural debería ser producido directamente en el SNC.

Algunas décadas atrás, la existencia de un metabolismo oxidativo del etanol en el SNC fue cuestionada, dada la dificultad de evaluar los niveles de acetaldehido en este tejido. Sin embargo, se han identificado

\footnotetext{
Usamos el término "receptor" en su vertiente más amplia. Es decir, como dianas moleculares capaces de reconocer otras moléculas y traducir dicho reconocimiento en un cambio en la fisiología celular.
} 
en el cerebro dos sistemas enzimáticos, la catalasa y el citocromo P4502E1, capaces de llevar a cabo esta transformación metabólica a las concentraciones de etanol que, en dicho tejido, se alcanzan después de su consumo. Asimismo, las mejoras técnicas han permitido la detección de la formación de acetaldehido en tejido neural, incluso in vivo. De este modo, se ha revitalizado la hipótesis de que este metabolito pudiera mediar algunos de los efectos fisiológicos y conductuales observados tras la administración de etanol, delimitando además que el acetaldehído "psicofarmacológicamente relevante" sería aquel producido directamente en el SNC.

Numerosos trabajos, tanto in vitro como in vivo, han aportado pruebas de esta oxidación central del etanol. En los estudios in vitro, se ha podido constatar que tras la incubación de tejido neural con etanol se produce acetaldehído. La presencia de inhibidores de la catalasa en estas incubaciones causa un decremento en la formación de acetaldehido. Otros estudios en los se que dichos inhibidores se administran in vivo, han analizado la producción de acetaldehido en los homogeneizados cerebrales de roedores después una incubación con etanol, y han comprobado que ambos inhibidores bloquean de manera dependiente de la dosis la producción de acetaldehido. Otro tipo de pruebas procede de la utilización de subestirpes de ratones génicamente diferentes en los niveles de catalasa: ratones normales versus ratones acatalasémicos. Los homogenados de cerebro procedentes de ratones normales e incubados con etanol producen más acetaldehido que los homogeneizados procedentes de ratones acatalasémicos. Recientemente, se ha demostrado la acumulación diferente de acetaldehido en distintas estructuras del cerebro de ratas tras ser incubadas con etanol, siendo ésta más prominente en aquellas estructuras cerebrales, donde se encuentra más cantidad de catalasa. En definitiva, estos trabajos han establecido que la catalasa es una vía plausible de metabolismo oxidativo del etanol en el SNC, describiendo así un mecanismo por el cual se produce acetaldehído en el SNC. Por otra parte, existen elementos sólidos para descartar la participación del enzima ADH, mientras que el posible papel que pudiera jugar el citocromo P4502E1 requiere más investigación. Los lectores interesados pueden hallar un resumen de los hallazgos experimentales que apoyan la existencia de un metabolismo del etanol en el SNC en el trabajo de Zimatkin y Dietrich (1997)

\section{DEL ACETALDEHÍDO A “LA HIPÓTESIS DEL ACETALDEHÍDO"}

La mera producción de acetaldehído en el SNC no aporta indicio alguno acerca de su posible concurso en las acciones psicofarmacológicas derivadas del consumo/ administración de etanol. En este sentido, una de las razones fundamentales que sustentan esta idea es la probada capacidad del acetaldehído para reproducir algunos de los efectos psicofarmacológicos que se observan tras el consumo de etanol en diferentes modelos y tests usados en la investigación preclínica. Así, y aun cuando el acetaldehído no es ingerido oralmente, ha quedado claramente establecido que los roedores aprenden y mantienen conductas dirigidas a su consumo por otras vías de administración, especialmente aquellas que posibilitan su incorporación directa al SNC. Es decir, el acetaldehído (al igual que el etanol y el resto de las drogas de abuso) parece ser capaz de comportarse como un reforzador. Este hecho no es trivial, por cuanto actualmente se considera que la capacidad de las drogas de abuso para actuar como reforzadores es el principio que dirige y mantiene el consumo no-compulsivo de las mismas ${ }^{2}$.

El consumo voluntario es una manera directa de evaluar la capacidad de una droga para actuar como un reforzador, sin embargo el reforzamiento es un proceso complejo y la capacidad de un estímulo (ej. una droga) para actuar como un reforzador depende de su capacidad para promover diferentes tipos de acciones que pueden agruparse o describirse como 3 grandes funciones: la función activadora, la función emocional y la función motivadora. En este sentido, actualmente disponemos de indicios experimentales suficientes para afirmar que el acetaldehído no sólo es susceptible de consumo cuando se provee una vía de administración correcta, sino que además

\footnotetext{
2 Actualmente ha quedado claramente establecida la noción de que el consumo prolongado de una sustancia es cualitativamente diferente al consumo compulsivo y/o adicción de la misma. El primero sería un fenómeno susceptible de ocurrencia en cualquier individuo, dependiente en gran medida de la capacidad de estas sustancias para actuar como reforzadores positivos (de forma similar a los llamados "reforzadores naturales"; ej. Comida, sexo). Por el contrario, la adicción supone un estadío final de una serie de transiciones que sólo acontecen en un número limitado de consumidores crónicos de dichas sustancias. La adicción se caracteriza por una pérdida de control sobre las conductas de búsqueda y consumo de drogas, que devienen compulsivas mediante mecanismos que trascienden la habilidad de estas sustancias para actuar como reforzadores. En este sentido, es posible afirmar que no todos los estímulos que actúan como reforzadores son capaces de promover adicción. Además, y como acabamos de comentar, no todos los individuos que exhiben conductas reforzadas mediante drogas de abuso devienen adictos a las mismas por lo que, posiblemente, no pueda considerarse que la capacidad de promover adicción sea una característica exclusiva de ciertas drogas sino que requiere de una "susceptibilidad" del individuo.
} 
es capaz de promover una activación del SNC que, posiblemente junto a su capacidad de producir efectos subjetivos "positivos" 3 , contribuye a la selección y vigorización de conductas dirigidas a una meta: su consumo.

Así, el acetaldehído es un potente activador conductual. Una forma sencilla y objetiva de evaluar esta capacidad del acetaldehído (y otras sustancias psicoactivas) es el observar las consecuencias de su administración en la actividad locomotora de roedores. En este sentido, se ha podido constatar que, al igual que el etanol, la administración de acetaldehído aumenta dicha locomoción, al menos cuando esta se produce directamente en el SNC. Además, diferentes estudios farmacológicos y farmacogenéticos han demostrado que la capacidad que el etanol posee para incrementar la locomoción de ratones es dependiente y proporcional a la actividad de la catalasa cerebral, e inversa a la actividad del enzima ALDH (enzimas que controlan la producción y degradación del acetaldehído en el SNC, respectivamente). Por otra parte, la función activadora de los reforzadores queda también reflejada en su capacidad para fortalecer aprendizajes que no implican ninguna relación de contingencia con los mismos. En este sentido, se ha demostrado que administraciones no-contingentes del etanol mejoran el aprendizaje que permite el reconocimiento social entre roedores y que dicha capacidad es posiblemente "acetaldehídodependiente" en tanto que es proporcional a la actividad del enzima catalasa.

Debido a su propia naturaleza interna, la capacidad de producir estados subjetivos "positivos" no puede evaluarse directamente y aún menos cuando los sujetos experimentales no son capaces de informar verbalmente acerca de los mismos. Sin embargo, dichos estados si producen consecuencias comportamentales que pueden ser evaluadas con objetividad y de las cuales podemos hipotetizar su valencia emocional. De entre éstas, una de las más básicas y utilizadas en la investigación preclínica, es la capacidad de promover "aproximación/ evitación pavloviana". Este término se refiere a la capacidad adquirida de estímulos inicialmente neutros para promover respuestas de acercamiento/ evitación a partir de su asociación repetida y contingente con reforzadores positivos o con estímulos aversivos, respectivamente. Este fenómeno, que combina aspectos emocionales -y también motivacionales (en tanto que establece nuevos objetivos para la conducta en virtud de los primeros)- puede medirse mediante diversos procedimientos experimentales como la preferencia de lugar condicionada. En este sentido, de forma similar a lo referido en cuanto a la función activadora, se ha demostrado que el acetaldehído es capaz de promover preferencia de lugar y que la capacidad del etanol para promover dicho efecto es dependiente de la actividad de la catalasa cerebral. Además, la capacidad del etanol de reducir estados subjetivos negativos (ej. Ansiedad) parece ser también dependiente de la actividad de este sistema enzimático.

Finalmente, ya se ha comentado con anterioridad que el acetaldehído es una sustancia susceptible de autoadministración, permitiendo la instauración y mantenimiento de comportamientos que posibilitan su consumo. Este hecho demuestra su capacidad de establecerse como un objetivo (meta) conductual per se, esto es, su función motivacional. Además, cabe mencionar que la administración de acetaldehído facilita el consumo de etanol. Asimismo, la ingesta de etanol es dependiente de la actividad del enzima catalasa, ya que inhibidores de este sistema enzimático disminuyen el consumo de esta sustancia.

Así, tomados en su conjunto, todos estos datos sugieren que el acetaldehído es una sustancia psicoactiva, capaz de actuar como un reforzador, en tanto que posee funciones activadoras, emocionales y motivacionales. Además, el hecho de que la capacidad del etanol para promover dichas funciones sea directa/ inversamente proporcional a la actividad de los sistemas enzimáticos que posibilitan su síntesis y degradación en el SNC respectivamente, parecen sugerir que el acetaldehído cerebral podría ser el agente farmacológico responsable de dicha capacidad "del etanol". Es decir, parece que los efectos reforzadores observados tras la administración/ consumo del etanol serían en realidad consecuencias de su transformación a acetaldehído. Un comentario más pormenorizado de los hallazgos experimentales que sustentan esta hipótesis

La capacidad de las drogas de abuso para producir estados internos "positivos" (a menudo descritos como "placer" y "euforia") sólo puede ser hipotetizado en animales incapaces de informar verbalmente de los mismos. En este sentido, en la investigación preclínica, existe un creciente interés en abordar la capacidad reforzante de las drogas de abuso sin hacer referencia directa a este tipo de estados internos de difícil y subjetiva cuantificación. Un tratamiento más extenso de este tema y sus implicaciones metodológicas puede ser consultado en Sanchis-Segura and Spangel. Addict. Biol. 2006. 11: 1-43 y los comentarios asociados a este trabajo de revisión.

Por otra parte, proponer al acetaldehído como el agente que podría propiciar reforzamiento e incluso estados internos "positivos", puede resultar sorprendente. Así, terapias disuasorias o de castigo basada en el uso de inhibidores del enzima ALDH (ej. Disulfiram) han intentado promover un malestar físico mediante la acumulación de acetaldehído. Sin embargo, y como se ha mantenido a lo largo de este comentario, es más que posible que el acetaldehído formado central opere a través de mecanismos y produzca consecuencias opuestas a la acumulación sistémica de acetaldehído. Así, el acetaldehído formado periféricamente podría ser un agente aversivo, mediante que el mismo agente, cuando se forma e interactúa con el SNC, parece actuar como un estímulo apetitivo. 
puede encontrarse en Smith, Aragón y Amit (1997) o en Quertemont, Tambour y Tirelli (2005).

\section{¿ALCOHOLISMO O ACETALDEHISMO? IMPLICA- CIONES DE LA “HIPÓTESIS DEL ACETALDEHÍDO”}

La capacidad reforzadora de una droga es la que inicia y mantiene su consumo. En lo referido al etanol, parece que dicha capacidad reforzadora depende de su transformación (oxidación) a acetaldehído en el SNC. Aceptar estas premisas conduce a la idea de que el acetaldehído sería el agente psicofarmacológico responsable del consumo de esta sustancia, aunque no necesariamente a la conclusión de que todas y cada unas de las consecuencias derivadas del consumo/administración de etanol dependen de la formación de acetaldehído.

La "hipótesis del acetaldehído" ha sido presentada desde diferentes perspectivas, pero la mayor parte de ellas sugieren que los efectos conductuales derivados del consumo/ administración del etanol serían el resultado final de la acción combinada (en algunos casos sinérgica, en otras antagónica) de los efectos del etanol, el acetaldehído y, quizás, el ácido acético (metabolito obtenido tras la oxidación del acetaldehído) sobre el sustrato neural. Desde esta perspectiva, cada una de estas moléculas podría poseer una contribución diferencial en los diferentes efectos conductuales y fisiológicos derivados del consumo/ administración de etanol. Asi, existen efectos que podrían poder ser descritos como "efectos del etanol", ya que no parecen requerir del metabolismo oxidativo de esta sustancia y cuya magnitud no parece verse afectada por la manipulación de los sistemas enzimáticos que la controlan. Un ejemplo de este tipo de fenómeno sería la incoordinación motora asociada a la intoxicación etílica. Asimismo, existen otras consecuencias funcionales observadas tras la administración/ consumo de etanol que también parecen ser consecuencias derivadas de los efectos del etanol sobre el sustrato neural, pero en los que la formación de acetaldehído (en los mismos o en otros circuitos neurofisiológicos) pudiera tener una modulación negativa de los mismos. Esta es la conclusión que cabe extraer tras haberse observado que la inhibición de la actividad del enzima catalasa en el SNC (y, en consecuencia, la disminución en la producción de acetaldehído cerebral) incrementa la liberación de corticosterona así como la latencia de recuperación del llamado "reflejo de enderezamiento". Por otra parte, y como se ha comentado con anterioridad, algunas de las consecuencias funcionales observadas tras el consumo/ administración de etanol (ej. Reforzamiento), debieran ser considerados como "efectos del acetaldehído cerebral" en tanto que son reproducidos por esta sustancia y presentan una clara dependencia respecto de los sistemas que posibilitan su formación en el SNC. Finalmente, si bien el ácido acético parece poseer ciertos efectos sobre el comportamiento de roedores en diferentes procedimientos experimentales, éstos han sido investigados en menor medida y en la actualidad es difícil precisar la posible contribución de esta sustancia en las consecuencias funcionales derivadas del consumo/ administración de etanol.

En este punto es importante señalar que la posible participación del acetaldehído en las consecuencias derivadas del consumo/ administración de etanol se han centrado en los efectos derivados de un exposición aguda o subcrónica a esta sustancia. En este sentido, parece claro que una de las áreas que requiere una investigación más exhaustiva es la posible implicación de esta sustancia en fenómenos tales como la tolerancia, la dependencia y el tránsito hacia la adicción. Así, la pregunta que titulaba este apartado del presente comentario sigue aún sin respuesta. Este hecho no significa, en absoluto, que nuestro conocimiento acerca de la contribución del metabolismo cerebral del etanol carezca de importantes implicaciones tanto para la investigación básica como aplicada del consumo de alcohol y sus consecuencias.

En primer lugar, desde esta perspectiva, aquellos sistemas enzimáticos que posibilitan la transformación del etanol a acetaldehído devienen "receptores" a nivel funcional. Es decir, permiten identificar aquellas estructuras cerebrales y grupos neuronales donde el etanol inicia una serie de cambios neurofisiológicos que, finalmente, llevan a una serie de efectos conductuales (al menos aquellos que hemos identificado como "acetaldehído-dependientes"). En este sentido, en los últimos años, nuestro grupo investigador ha iniciado una evaluación de esta hipótesis al evaluar la implicación de estructuras cerebrales que presentan una alta densidad, en cuando al nivel de expresión, del enzima catalasa. Así, hemos podido identificar que el núcleo Arqueado hipotalámico podría ser el locus anatómico de un mecanismo de acción en el que la oxidación del etanol y la consiguiente formación de acetaldehído posibilitan una liberación de opioides endógenos (b-endorfinas). Este hecho podría ser de gran interés dada la relevancia que este tipo de péptidos endógenos parece poseer en cuanto a los mecanismos de acción del etanol y su consumo, reflejada en la utilidad terapéutica que antagonistas de los receptores de estos opioides endógenos (naltrexona) en el manejo clínico del consumo excesivo de alcohol/ alcoholismo. Una descripción breve de los hallazgos en esta línea de trabajo puede encontrarse en Sanchis-Segura, Grisel, Olive, Ghozland, Koob, Roberts y Cowen, (2005).

En segundo lugar, la identificación de efectos "acetaldehído-dependientes" sugiere que variantes polimórficas en los enzimas que controlan su formación/ 
degradación podrían ser factores genéticos de predisposición/ protección respecto a un consumo abusivo de etanol. Así, nuestro grupo ha avanzado la propuesta de que variaciones en estos sistemas enzimáticos que se traduzcan en una producción y/o degradación más rápida del acetaldehído a nivel cerebral podrían ser factores que predispongan a un mayor consumo de esta droga. Por el contrario, variaciones que produzcan una producción/ degradación más lenta del acetaldehído podrían resultar en una reducción del consumo de etanol. En este sentido, cabe mencionar que disponemos aún de pocos datos, pero tanto en humanos como en roedores se han demostrado correlaciones significativas (en la dirección propuesta) entre el nivel de actividad de la catalasa y el ALDH y la cantidad de alcohol ingerido (Aragon y Amit ,1985; Aragón, Sternklar y Amit 1985; Koechling, Amit y Negrete 1995).

Finalmente, la consideración del acetaldehído como el agente responsable de algunos de los efectos del etanol y, en especial, de aquellos que delimitan su capacidad para actúar como un reforzador, podría habilitar nuevas formas de intervención terapéutica. Al menos teóricamente, el considerar la catalasa como un "receptor" funcional para el etanol provee de nuevas "dianas terapéuticas" a las que dirigir intervenciones farmacológicas destinadas a reducir los efectos reforzantes del etanol y, consecuentemente, su consumo futuro. En este sentido, es necesario mencionar que esta propuesta es un tanto especulativa, y que, pese a su atractivo inicial, el uso de inhibidores del enzima catalasa con este objetivo terapéutico podría no ser viable debido a sus efectos secundarios. De hecho, todos los inhibidores de este sistema enzimático conocidos presentan varios efectos indeseados que podrían desaconsejar su uso a largo plazo. Así, y en un intento de trascender dichos efectos, nuestro equipo ha demostrado que una alternativa más eficaz sería la "desactivación" del acetaldehído, la cual es posible mediante el uso de ciertos aminoácidos sulfurados como la Dpenicilamina.

Una de las características moleculares más interesantes de la D-penicilamina es que posee grupos sulfidrilos libres, lo que dota a la molécula de una gran afinidad por el cobre,el plomo y el zinc, pero también por los grupos aldehídos. En este sentido, algunos laboratorios han demostrado en repetidas ocasiones la interacción del acetaldehído con algunos aminoácidos tioles formando productos de condensación (tiazolidinas) lo que supone una desactivación funcional del acetaldehído. En este sentido, nuestro grupo investigador ha demostrado que la administración (cerebral o sistémica) de penicilamina reduce el consumo voluntario de etanol y la capacidad de esta droga para producir preferencia de lugar condicionada o cambios en la conducta motora de roedores (Font, Miquel y Aragón 2005, 2006a, 2006b). Es decir, al ser capaz de “secuestrar el acetaldehído cerebral, la administración de este aminoácido bloquea los efectos reforzantes del etanol (en sus tres grandes funciones: motivacional, emocional y activadora). Además, y reforzando la idea de su posible utilidad terapéutica, merece la pena mencionar que esta sustancia es inerte (no se degrada) por lo que puede permanecer "a la espera" del acetaldehído períodos de tiempo relativamente largos. Además, no presenta efectos indeseables destacables (de hecho, se esta explorando el uso para otras enfermedades y trastornos) y es bien tolerada incluso cuando se administra de forma crónica. Asimismo, y dado que interviene secuestrando el acetaldehído producido independientemente del sistema enzimático responsable de su formación, podría presentar utilidad terapéutica para otros efectos asociados al acetaldehído tales como la toxicidad en diferentes órganos corporales (incluido el cerebro).

\section{CONCLUSIONES}

En el presente comentario se han presentado brevemente las hipótesis que guían una importante línea de investigación respecto a los posibles mecanismos de acción del etanol en el SNC, la llamada "hipótesis del acetaldehído". Además, se ha hecho un resumen de algunos de los indicios que sustentan esta hipótesis y evaluaremos las posibles implicaciones que la confirmación de la misma pudiera tener para nuestra comprensión de los básicos de acción de esta sustancia y para la terapéutica del consumo excesivo de alcohol y consecuencias asociadas. Respecto a estas últimas, estrategias terapeúticas basadas en la inhibición de los enzimas que controlan la formación de acetaldehído en el SNC (catalasa) podrían no ser viables. Sin embargo, la desactivación de esta sustancia mediante otro tipo de agentes (ej. Aminoácidos tioles como la pencilamina) parecen más plausibles.

\section{REFERENCIAS}

Aragón, C. M. y Amit, Z. A two dimensional model of alcohol consumption: possible interaction of brain catalase and aldehyde dehydrogenase. Alcohol. 1985 Mar-Apr; 2:357-60.

Aragón, C. M., Sternklar, G. y Amit Z. A correlation between voluntary ethanol consumption and brain catalase activity in the rat. Alcohol. 1985. 353-356.

Font, L., Aragón, C. M. y Miquel, M. Ethanol-induced conditioned place preference, but not aversion, is blocked bytreatment with D -penicillamine, an inactivation agent for acetaldehyde. Psychopharmacology 2006a. 184: 56-64. 
Font. L., Aragón, C. M. y Miquel, M. Voluntary ethanol consumption decreases after the inactivation of central acetaldehyde by d-penicillamine. Behav Brain Res. 177: 78-86. Epub 2006 Apr 18.

Font, L., Miquel, M. y Aragón, C. M. Prevention of ethanolinduced behavioral stimulation by D-penicillamine: a sequestration agent for acetaldehyde. Alcohol Clin Exp Res. 2005. 29: 1156-1164.

Koechling, U. M., Amit, Z. y Negrete, J. C. Family history of alcoholism and the mediation of alcohol intake by catalase: further evidence for catalase as a marker of the propensity to ingest alcohol. Alcohol Clin Exp Res. 1995. 19: 1096-1104.

Quertemont, E., Tambour, S. y Tirelli, E. The role of acetaldehyde in the neurobehavioral effects of ethanol: a comprehensive review of animal studies. Prog Neurobiol. 2005. 75: 247-274.

Sanchis-Segura, C., Grisel, J. E., Olive, M. F., Ghozland, S., Koob, G. F., Roberts, A. J. y Cowen, M. S. Role of the endogenous opioid system on the neuropsychopharmacological effects of ethanol: new insights about an old question. Alcohol Clin Exp Res. 2005 Aug; 29:1522-7.

Smith, B. R., Aragón, C. M. G., Amit, Z. Catalase and the production of central acetaldehyde: A possible mediator of the psychopharmacological effects of ethanol. Addict. Biol. 1997. 2: 277-289

Zimatkin, S. M. y Deitrich, R. A. Ethanol metabolism in the brain. Addict. Biol. 1997. 2: 387-399. 
